\title{
Glycyrrhizic Acid Attenuates Sepsis-Induced Acute Kidney Injury by Inhibiting NF- $\kappa$ B Signaling Pathway
}

\author{
Hongyu Zhao, Min Zhao, Yu Wang, Fengchun Li, and Zhigang Zhang \\ Department of Emergency Medicine, Shengjing Hospital of China Medical University, 36 Sanhao Street, Shenyang 110004, China \\ Correspondence should be addressed to Hongyu Zhao; zhaohongyuz@163.com
}

Received 17 April 2015; Accepted 5 July 2015

Academic Editor: José L. Ríos

Copyright (C) 2016 Hongyu Zhao et al. This is an open access article distributed under the Creative Commons Attribution License, which permits unrestricted use, distribution, and reproduction in any medium, provided the original work is properly cited.

\begin{abstract}
Glycyrrhizic acid (GA) is a major active ingredient in licorice. In our study, the effects of GA on acute kidney injury (AKI) in rats and its underlying molecular mechanisms were investigated. The sepsis model was produced by caecal ligation and puncture (CLP) in rats. The molecular and histological experiments were performed in the kidney tissues and serum samples of rats. According to the results obtained, GA alleviated sepsis-induced AKI by improving the pathological changes, decreasing the levels of blood urea nitrogen (BUN), creatinine (Cre), and increasing the survival rate of rats with AKI significantly. The production of inflammatory cytokines, such as TNF- $\alpha$, IL-1 $\beta$, and IL-6, was markedly inhibited by GA. Moreover, treatment with GA inhibited the production of nitric oxide (NO) and prostaglandin E2 (PGE2) and expression levels of induced nitric oxide synthase (iNOS) and cyclooxygenase2 (COX-2) in kidney tissues. Furtherly, the apoptosis in kidney tissue induced by AKI was suppressed by GA. Finally, GA could inhibit the activation of NF- $\kappa$ B signaling pathway. Our study suggests that GA alleviates sepsis-induced AKI by inhibiting the $\mathrm{NF}-\kappa \mathrm{B}$ signaling pathway, which provides a strong evidence for a new approach for treating sepsis-induced AKI.
\end{abstract}

\section{Introduction}

Sepsis is a systemic inflammatory response syndrome (SIRS) induced by infection [1]. Despite improvement in the clinical technology for intensive care, the mortality rate induced by sepsis in intensive care units remains high [2-4]. The latest epidemiological studies show that each year more than 18 million people are infected by severe sepsis in the world and the number is rising at an annual rate of $1.5 \% \sim 8.0 \%$. The mortality rate is especially remarkable, ranging up to $60 \%$. Sepsis, in severe cases, may progress to organ failure and death [5]. About $42 \%$ patients with sepsis may experience AKI [6], and AKI is an independent factor of mortality in sepsis. Since the mortality rate is as high as 70\% [7], sepsisinduced AKI is one of the critical urgent problems in critical care medicine and nephrology. So far, it has been known that there are many aspects about the pathophysiological mechanisms of sepsis-induced AKI: vasodilation-induced glomerular hypoperfusion, dysregulated circulation within the peritubular capillary network, apoptosis of kidney cells, inflammatory reactions by cytokines overproduction, and oxidative stress-induced tubular dysfunction [8].

GA, a primary bioactive constituent of the shrub Glycyrrhiza glabra's roots, has strong and extensive effects on immunomodulatory, antiparasitic, antioxidant, antiviral, and antitumor activities [9-13]. At present, GA is widely used in Asia as a therapeutic agent for chronic viral hepatitis [14, 15]. Recent studies also have shown that GA has a variety of protective effects on kidney. For example, research found that GA had therapeutic effect on experimental obstructive nephropathy in rats [16]. In addition, GA also can protect renal tubular epithelial cells against injury induced by high glucose [17]. The study by $\mathrm{Bi}$ et al. has also shown that glycyrrhizin had protective effect on nephrotic syndrome induced by adriamycin in rats [18]. However, the effect of GA on sepsis-induced AKI and its related molecular mechanisms have been poorly understood so far.

In the present study, we aim at observing the beneficial effect of GA on sepsis-induced AKI and analyzing the detailed molecular mechanisms in a sepsis rat model by 


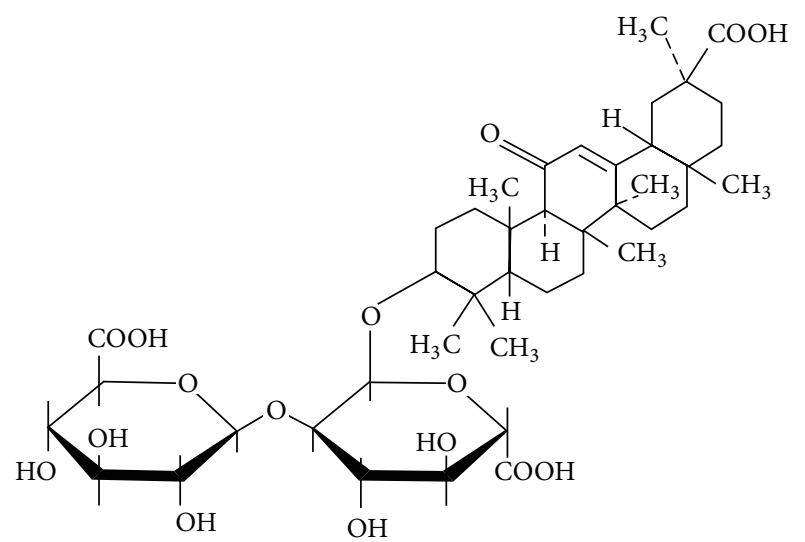

Figure 1: Chemical structure of GA. The molecular formula of GA is $\mathrm{C}_{42} \mathrm{H}_{62} \mathrm{O}_{16}$ and its molecular weight is 822.93 .

caecal ligation and puncture (CLP), which is recognized as having strong clinical relevance [19].

\section{Materials and Methods}

2.1. Drugs and Antibodies. GA was purchased from Meilun Biological Co., Ltd. (Dalian, China), and dissolved in 10\% DMSO at a concentration of $5 \mathrm{mg} / \mathrm{mL}$. The chemical structure of GA is shown in Figure 1. The antibodies used for western blotting and immunohistochemistry were as follows: antiBcl-2 (Boster, China), anti-Bax (Boster, China), anti-I $\kappa \mathrm{B} \alpha$ (Bioss, China), anti-cleaved caspase-3 (Abcam, USA), antiNF- $\kappa$ B (Boster, China), anti-p-NF- $\kappa$ B (Bioss, China), antiCox-2 (Boster, China), anti-iNOS (Bioss, China), anti- $\beta$ actin (Boster, China), and anti-Histone H3 (Bioss, China).

2.2. Animals and Experimental Protocol. Pathogen-free male Sprague-Dawley rats (weight $200 \pm 20 \mathrm{~g}$ ) were purchased from Beijing Vital River Laboratory Animal Co., Ltd. (Beijing, China). The animals were maintained at $23^{\circ} \mathrm{C}$ under a $12 \mathrm{~h}$ light-dark cycle with free access to food and water. The night before the experiments, animals had no access to food but gained free access to water. 50 rats were randomly divided into five experimental groups ( $n=10$ per group): sham operation group, GA (50 mg/kg) group, sepsis group, sepsis plus GA $(25 \mathrm{mg} / \mathrm{kg})$, and sepsis plus GA (50 mg/kg). We constructed sepsis model by CLP. Briefly, the rats were anaesthetized by injection of sodium pentobarbital $(50 \mathrm{mg} / \mathrm{kg})$ and a laparotomy was performed through a $2 \mathrm{~cm}$ ventral midline abdominal incision. We punctured the cecum twice at different sites with an 18-gauge needle and gently compressed until faces were extruded and then repositioned it. The incision was closed in 2 layers. The sham operation group underwent laparotomy through a midline incision, but the cecum was not punctured. Animals in the GA $(50 \mathrm{mg} / \mathrm{kg})$ group, sepsis plus GA (25 mg/kg) group, and sepsis plus GA (50 mg/kg) group were intraperitoneally injected with GA $25 \mathrm{mg} / \mathrm{kg}$ or $50 \mathrm{mg} / \mathrm{kg}$, while sham operation group and sepsis group were intraperitoneally injected with isovolumetric normal saline. $24 \mathrm{~h}$ after surgery, all the animals were euthanized and peripheral blood and kidney tissues were collected for further tests. All animal experiments were carried out strictly in accordance with international ethical guidelines and the National Institutes of Health Guide concerning the Care and Use of Laboratory Animals. The experiments were approved by the Institutional Animal Care and Use Committee of Shengjing Hospital of China Medical University.

2.3. Survival Curves. To observe the effect of GA on survival, another 40 rats were randomly divided into four experimental groups ( $n=10$ per group): sham operation group, sepsis group, sepsis plus GA ( $25 \mathrm{mg} / \mathrm{kg}$ ) group, and sepsis plus GA (50 $\mathrm{mg} / \mathrm{kg}$ ) group. The observation of survival was performed every $12 \mathrm{~h}$ until the endpoint at $96 \mathrm{~h}$.

2.4. Periodic Acid-Schiff (PAS) Staining. The kidney tissue samples were fixed in $10 \%$ buffered formalin for $48 \mathrm{~h}$ and were then dehydrated by washing with ascending grades of ethanol. Then, samples were sectioned and embedded in paraffin wax. $5 \mu \mathrm{m}$ kidney sections were prepared for routine PAS stains. The morphologic change of kidney was assessed by staining with PAS. Under $400 \mathrm{x}$ magnification, each section was randomly selected and photographed for 5 fields. The kidney injury was assessed by the following criteria, referred to in previous method [20]: 0, normal; 1, damage involving less than $25 \%$ of the area; 2 , damage involving $25 \%$ to $50 \%$ of the area; 3, damage involving $50 \%$ to $75 \%$ of the area; $4,75 \%$ to $100 \%$ of the area being affected.

2.5. Serum Analysis. Blood samples collected following CLP were used for the detection of blood BUN and Cre levels using commercially available kits produced by Jiancheng Bioengineering Institute (Nanjing, China), following the instructions of the manufacturer. The concentrations of BUN and Cre were calculated by generating a standard curve.

2.6. Inflammatory Cytokine Measurement in Kidney. The levels of TNF- $\alpha$, IL- $1 \beta$, and IL- 6 in rats kidney tissues were measured by commercially available ELISA kits (Wanleibio, China) according to the manufacturer's instructions. The concentrations of TNF- $\alpha$, IL- $1 \beta$, and IL- 6 were determined by a standard curve and expressed as $\mathrm{pg} / \mathrm{mL}$.

2.7. Determination of NO. The amount of nitrite (a stable metabolite of NO) in the kidney tissues was detected by the Griess Reagent System (Beyotime, China) according to the manufacturer's recommendation. Absorbance was measured at $540 \mathrm{~nm}$ and the nitrite concentration was determined using various kalium nitrite concentrations $(1,2,5,10,20$, and $50 \mu \mathrm{M})$ as a standard.

2.8. Determination of $P G E_{2}$. The level of $\mathrm{PGE}_{2}$ in the kidney tissues was detected by commercially available ELISA kit (Wanlei, China) according to the manufacturer's recommendation. The concentration of $\mathrm{PGE}_{2}$ was determined by a standard curve and expressed as $\mathrm{pg} / \mathrm{mL}$. 
2.9. Terminal Deoxynucleotidyl Transferase-Mediated dUTP Nick End Labelling (TUNEL) Staining. The presence of apoptotic cells in kidney tissues was detected by TUNEL on rat kidney tissue sections using the DeadEnd Fluorometric TUNEL System (Promega, USA) following the manufacturer's protocols. The numbers of TUNEL-positive cells were counted from six sections under a microscope (400x).

2.10. Western Blot Analysis. Total proteins and nuclear proteins in the kidney tissues were extracted by commercially available kits (Beyotime, China) and then denatured. The protein concentration was determined by the $\mathrm{BCA}$ protein estimation kit (Beyotime, China). Equal quantities proteins samples were separated by SDS-PAGE and then transferred to polyvinylidene fluoride. The membranes were blocked with 5\% nonfat dry milk in PBS and incubated with antiBcl-2 (1:1000), anti-Bax $(1: 1000)$, anti-cleaved caspase-3 $(1: 1000)$, anti-I $\kappa \mathrm{B} \alpha(1: 1000)$, anti-NF- $\kappa \mathrm{B}(1: 1000)$, anti-pNF- $\kappa$ B (1:1000), anti-Cox-2 (1:1000), anti-iNOS (1:1000), anti- $\beta$-actin $(1: 1000)$, and anti-Histone $\mathrm{H} 3(1: 1000)$ antibodies, respectively, at $4^{\circ} \mathrm{C}$ overnight. The goat anti-rabbit secondary antibody conjugated with horseradish peroxidase $(1: 5000)$ was incubated. Results were carried out with ECL detection reagent (Beyotime, China). Photographs were taken and the optical densities of the bands were scanned and quantified with the Gel Doc 2000 (BioRad, USA).

2.11. Immunohistochemistry. The expressions of iNOS and COX-2 from different groups kidney tissues were detected by immunohistochemistry. The kidney tissues were fixed in $4 \%$ paraformaldehyde and then imbedded in paraffin. Kidney sections of $5 \mu \mathrm{m}$ were sectioned and placed on polyL-lysine-coated slides and then kept in an oven at $60^{\circ} \mathrm{C}$ for $24 \mathrm{~h}$ to increase section adherence to the slide. The slides were deparaffinized using xylene and dehydrated by graded concentrations of alcohol, then placed in a retrieval solution, and incubated in a microwave at high power for $15 \mathrm{~min}$. The slides were then cooled and washed with wash buffer and incubated sequentially with primary antibody and biotinlabeled secondary antibody. Finally, the sections were stained with $\mathrm{DAB}$, counterstained with hematoxylin, dehydrated, cleared in xylene, and fixed. Under 400x magnification, 5 different microscopic fields were randomly chosen.

2.12. Electrophoretic Mobility Shift Assay (EMSA). The tissues were homogenized and nuclear protein was extracted with a nuclear and cytoplasmic kit (Beyotime, China). Protein concentration was determined by the BCA protein estimation kit (Beyotime, China). The level of NF- $\kappa$ B in nucleus was then measured by EMSA. Briefly, nuclear protein samples were mixed with labeled DNA probe. The samples were loaded and run at $180 \mathrm{~V}$ for $80 \mathrm{~min}$. Following electrophoresis, protein was transferred from the gel to a positively charged nylon membrane by electroblotting. UV-cross-linked and biotinlabelled DNA was detected by chemiluminescence.

2.13. Statistical Analysis. All data are expressed as means \pm SD. One-way ANOVA followed by Bonferroni's post hoc test was used for comparisons among experiment groups. Survival data were analyzed utilizing log-rank or $\chi^{2}$. A $P$ value of less than 0.05 was considered statistically significant.

\section{Results}

3.1. Effect of GA against Sepsis-Induced AKI. To evaluate the histopathological morphologic changes of kidney, PAS staining assay was performed. As shown in Figure 2(a), the array of the epithelial cells of the proximal tubules is disorderly and obvious drop of epithelial cells could be seen, which resulted in the high tubular damage score in sepsis group. The glomerular volume became bigger, and mesangial cells showed swelling and glassy degeneration. However, GA restrained the pathological changes effectively. Moreover, serum BUN and Cre levels were measured to assess the overall kidney function. The results showed that the levels of BUN and Cre were significantly increased in sepsis group; however, GA could reduce them markedly (Figures 2(b) and 2(c)).

\subsection{Effect of GA on the Production of Inflammatory Cytokines.} Since the essence of sepsis is the inflammatory reactions, we detected the productions of inflammatory cytokines, such as TNF- $\alpha$, IL-1 $\beta$, and IL- 6 , in kidney tissue by ELISA. As shown in Figure 3, the productions of TNF- $\alpha$, IL- $1 \beta$, and IL- 6 were increased, induced by AKI, while treatment with GA could inhibit the excess productions of TNF- $\alpha$, IL-1 $\beta$, and IL- 6 .

\subsection{Effect of GA on the Productions of $\mathrm{NO}$ and $P G E_{2}$ and the} Expressions of iNOS and COX-2. To further justify the effect of GA on inflammatory reactions, the inflammatory mediators productions and proteins expressions were detected. As shown in Figure 4(a), sepsis resulted in a significant increase in NO production in kidney tissue compared with sham group, whereas GA significantly inhibited sepsis-induced production of NO. Moreover, immunohistochemical staining and western blot assay were used to evaluate the expression of iNOS. As shown in Figures 4(c) and 4(d), GA markedly inhibited sepsis-induced expression of iNOS in the same manner as it inhibited the production of NO.

Since COX-2 is one of the downstream targets of NO, which promotes the production of $\mathrm{PGE}_{2}$, the production of $\mathrm{PGE}_{2}$ and expression of COX-2 were evaluated subsequently. Our result showed that a significant increase in the production of $\mathrm{PGE}_{2}$ compared with sham operation group was induced by sepsis, whereas treatment with GA markedly inhibited sepsis-induced production of $\mathrm{PGE}_{2}$ (Figure 4(b)). Similarly, GA markedly inhibited sepsis-induced expression of COX-2 by immunohistochemical staining and western blot (Figures 4(e) and 4(f)).

3.4. Effect of GA on Renal Cell Apoptosis Induced by Sepsis. The apoptosis of kidney tissue was detected by TUNEL staining. As shown in Figure 5(a), compared with the sham group, the number of TUNEL-positive cells was increased significantly in the sepsis group, which could be inhibited by GA treatment. The statistics for each group were shown in Figure 5(b). To further confirm the effect of GA against 

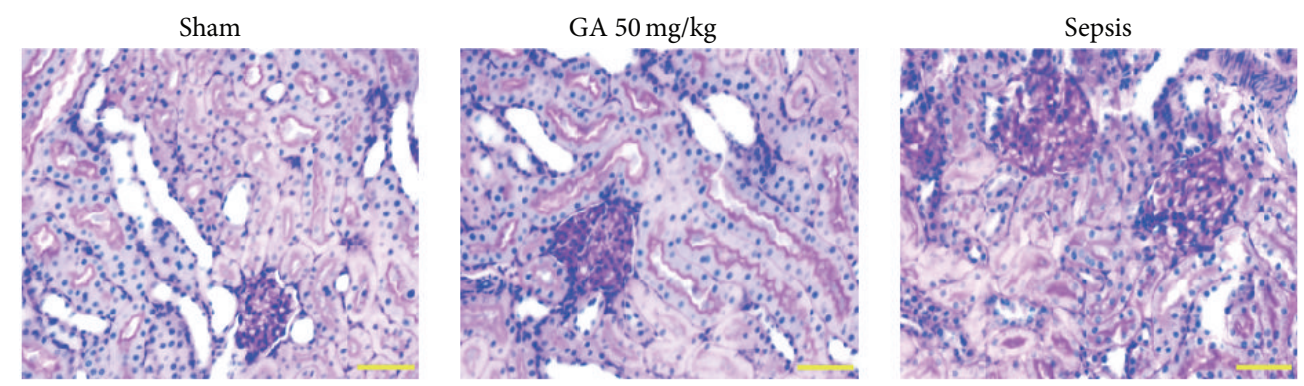

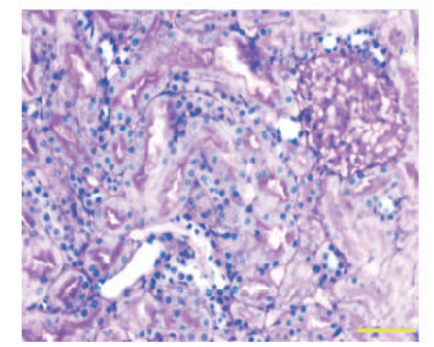

Sepsis + GA $25 \mathrm{mg} / \mathrm{kg}$

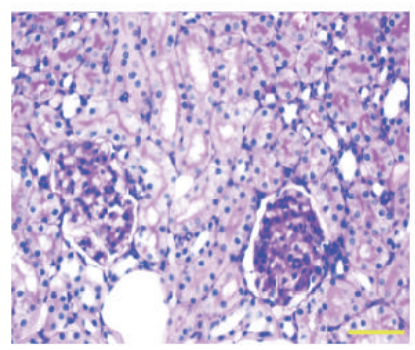

Sepsis + GA $50 \mathrm{mg} / \mathrm{kg}$
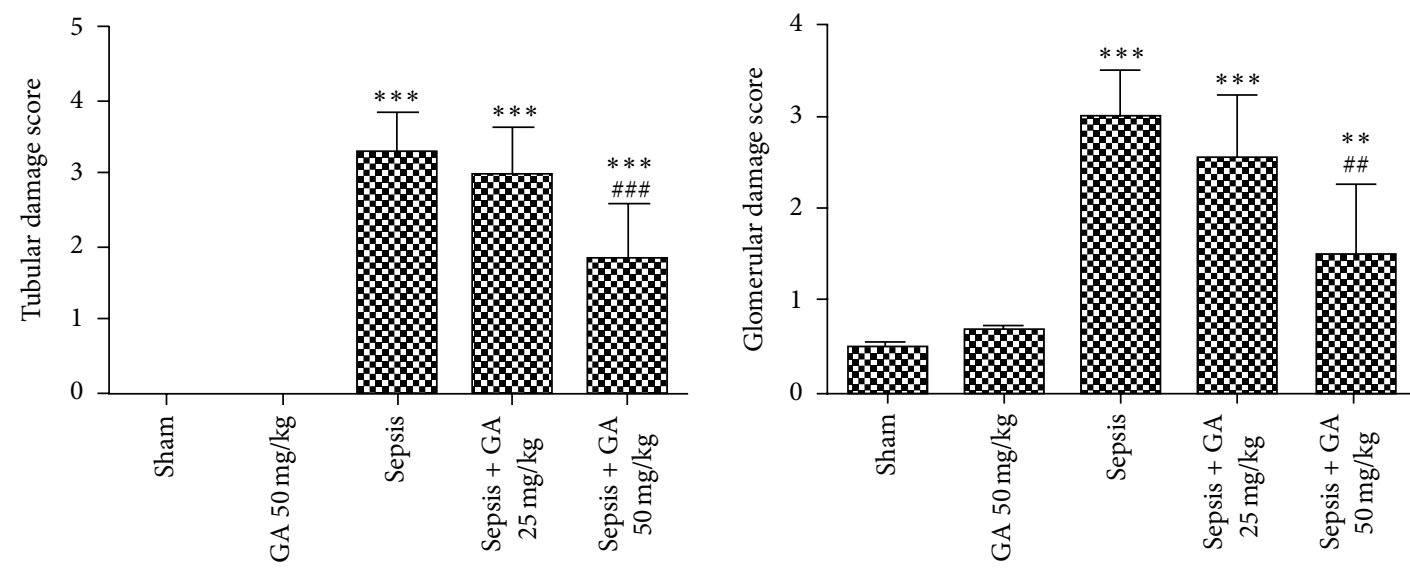

(a)

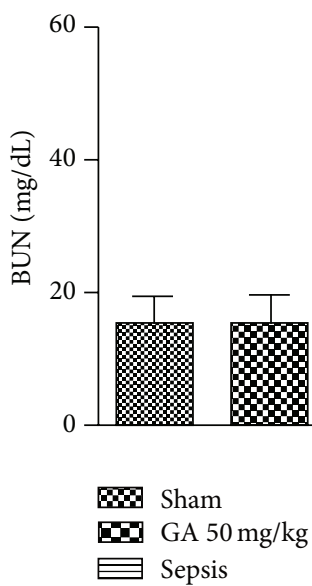

(b)

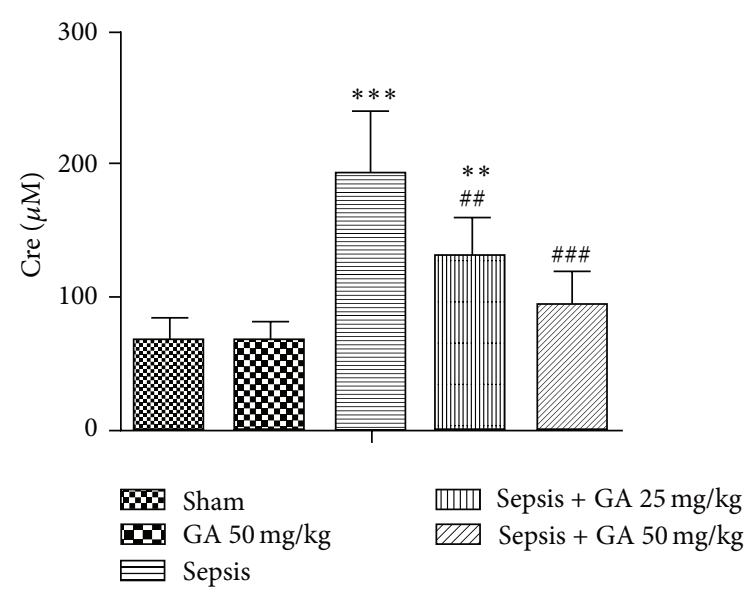

(c)

FIGURE 2: Protective effect of GA against sepsis-induced AKI and liver damage. (a) The pathological changes of kidney tissue were detected by PAS staining assay (magnification 400x) and the tubular injury score was shown. The serum concentrations of BUN (b) and Cre (c) from different groups. The results shown are representative of at least three independent experiments. Each value represents the mean $\pm \operatorname{SD}(n=6)$. ${ }^{*} P<0.05 ;{ }^{* *} P<0.01 ;{ }^{* *} P<0.001$, versus the sham operation group. ${ }^{\# \#} P<0.01$; ${ }^{\# \#} P<0.001$, versus the sepsis group. 


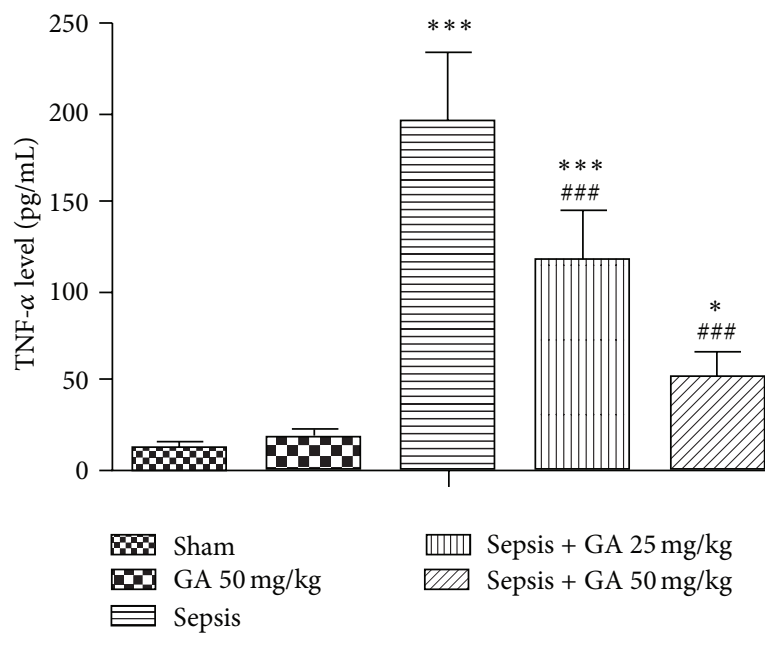

(a)

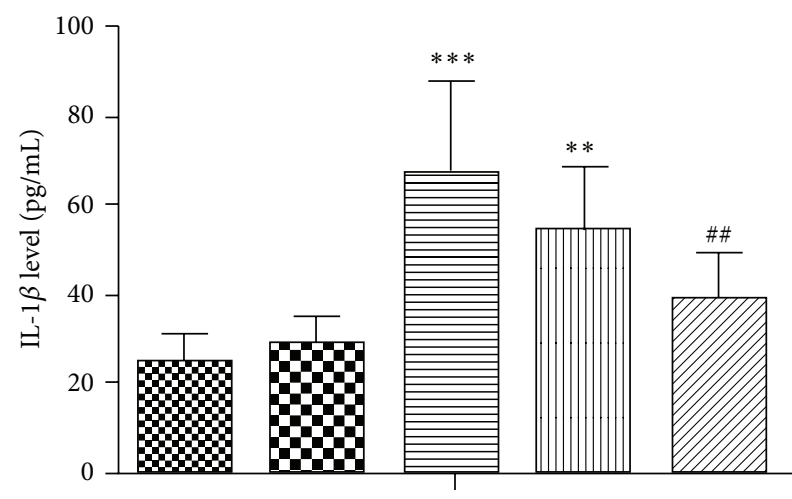
BA Sham
프 GA $50 \mathrm{mg} / \mathrm{kg}$
띠미 Sepsis + GA $25 \mathrm{mg} / \mathrm{kg}$
WII Sepsis + GA $50 \mathrm{mg} / \mathrm{kg}$

Sepsis

(b)

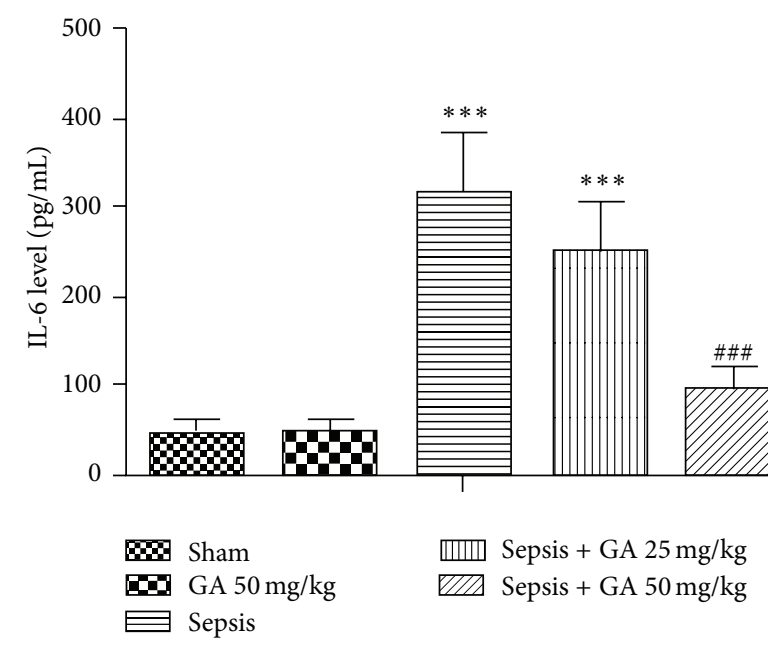

(c)

Figure 3: Effect of GA on inflammatory cytokines production. The TNF- $\alpha$ (a), IL-1 $\beta$ (b), and IL-6 (c) levels in kidney were determined by ELISA. The results shown are representative of at least three independent experiments. Each value represents the mean \pm SD $(n=6)$. ${ }^{*} P<0.05 ;{ }^{* *} P<0.01 ;{ }^{* * *} P<0.001$, versus the sham operation group. ${ }^{\# \#} P<0.01$; ${ }^{\# \# \#} P<0.001$, versus the sepsis group.

renal cell apoptosis, a number of apoptosis-related proteins in rat kidney were determined by western blot. As shown in Figure 5(c), in sepsis group, the expression of cleaved caspase3 protein was upregulated. The downregulation of $\mathrm{Bcl}-2$ and upregulation of Bax resulted in a significant decrease in the ratio of Bcl-2/Bax induced by sepsis. However, treatment with GA could downregulate the expression of cleaved caspase-3 and upregulate the ratio of $\mathrm{Bcl}-2 / \mathrm{Bax}$, compared with sepsis group.

3.5. GA Negatively Regulated the Activation of NF- $\kappa B$ Induced by $A K I$. NF- $\kappa \mathrm{B}$, a key transcriptional regulatory factor, participates in inflammatory reactions and plays important roles in the disease course. So various assays were adopted to evaluate the effects of GA on the activation of NF- $\kappa \mathrm{B}$. As assessed by western blot and shown in Figure 6(a), we found that the expression of $\mathrm{I} \kappa \mathrm{B} \alpha$ was decreased, while the expressions of $\mathrm{p}-\mathrm{NF}-\kappa \mathrm{B}$ and $\mathrm{NF}-\kappa \mathrm{B}$ in nucleus were increased significantly in sepsis group, compared with sham group, which demonstrated the activation of NF- $\kappa$ B induced by AKI. However, these changes induced by AKI were inverted by GA treatment. Moreover, EMSA assay was performed to further demonstrate the role of GA in regulating the activity of NF$\kappa \mathrm{B}$ binding to DNA. The EMSA results clearly showed the activation of NF- $\kappa$ B in the sepsis group, while GA could significantly inhibit the activation of NF- $\kappa \mathrm{B}$ (Figure $6(\mathrm{~b})$ ).

3.6. Effect of GA on Survival Rate. To further confirm the protective effect of GA on sepsis-induced AKI, we detected the survival rate of rats in different treatment groups. As shown in Figure 7, the survival rate of rats in sepsis-induced AKI was significantly decreased compared with sham operation group, which was greatly improved by GA treatment, confirming the effectiveness of GA furtherly. 


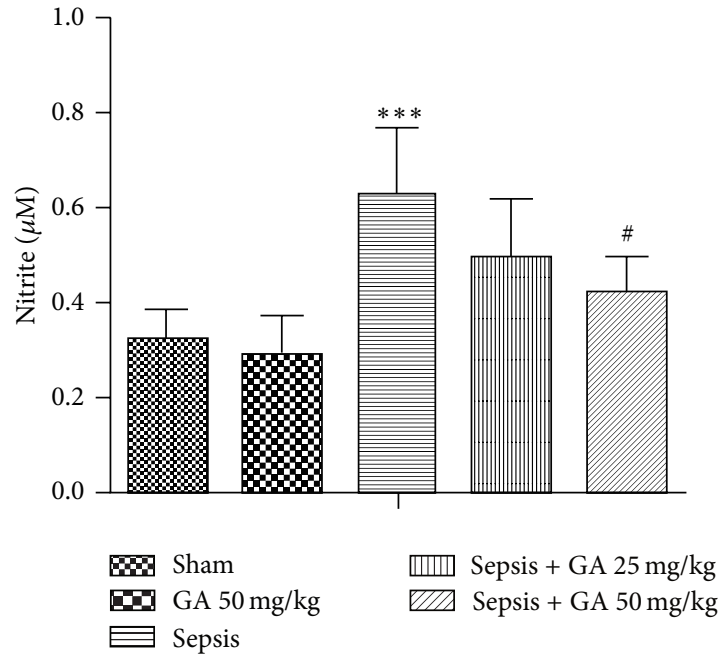

(a)
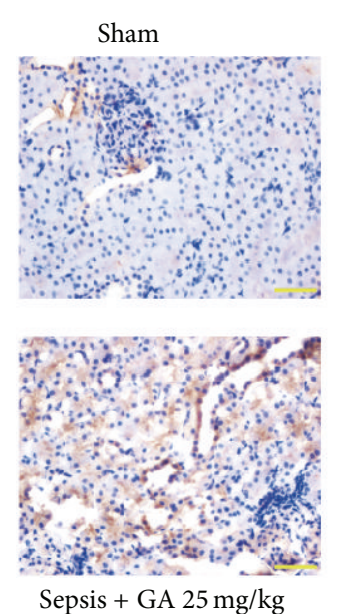

Sepsis + GA 25 mg/kg
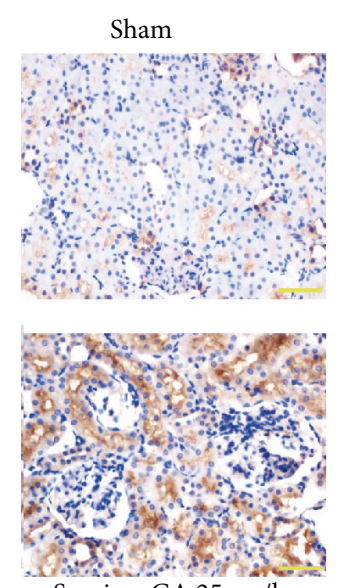

Sepsis + GA 25 mg/kg
GA $50 \mathrm{mg} / \mathrm{kg}$
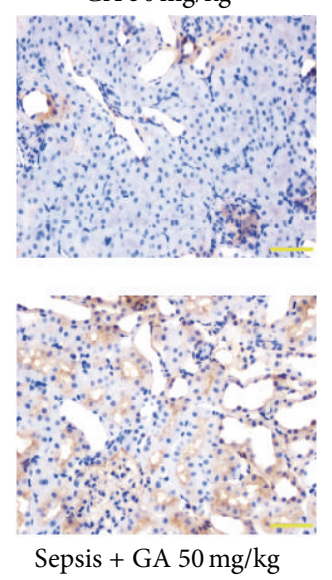

(c)

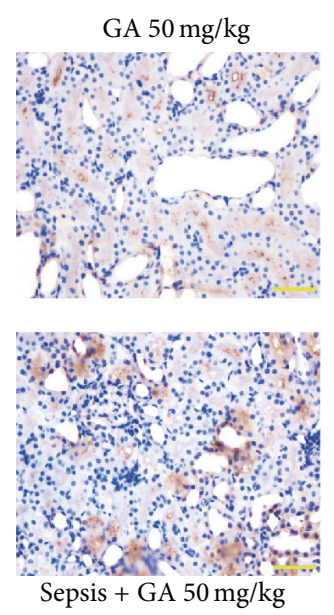

(e)
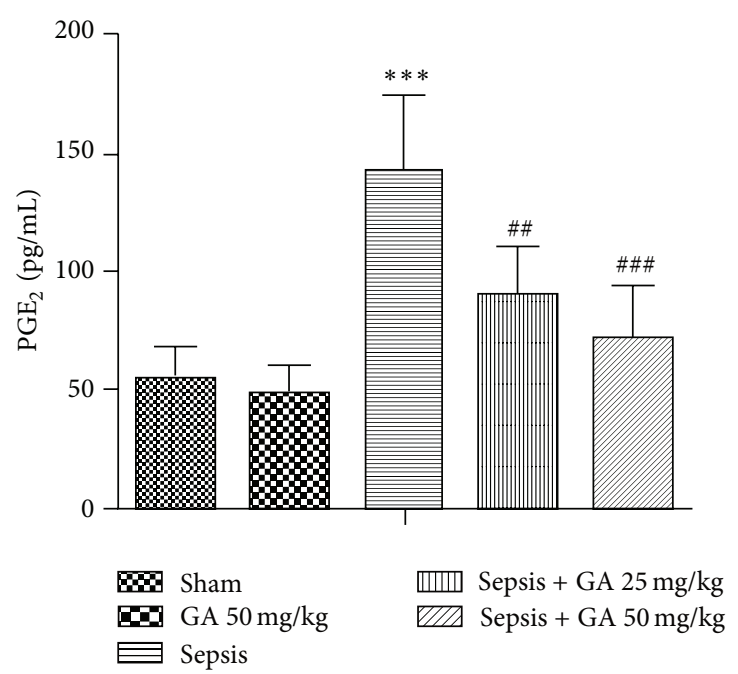

(b)

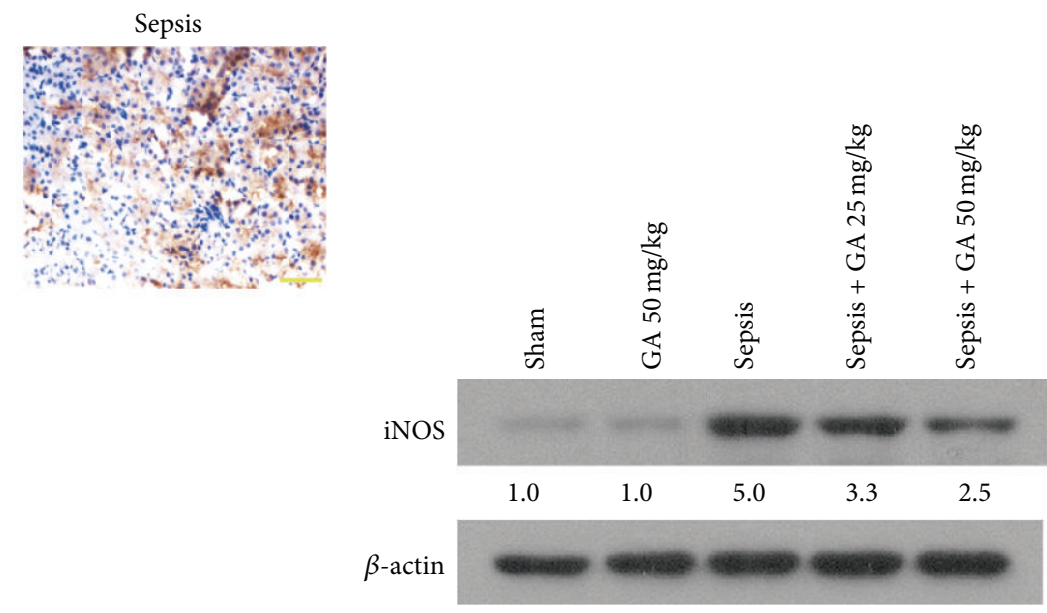

(d)
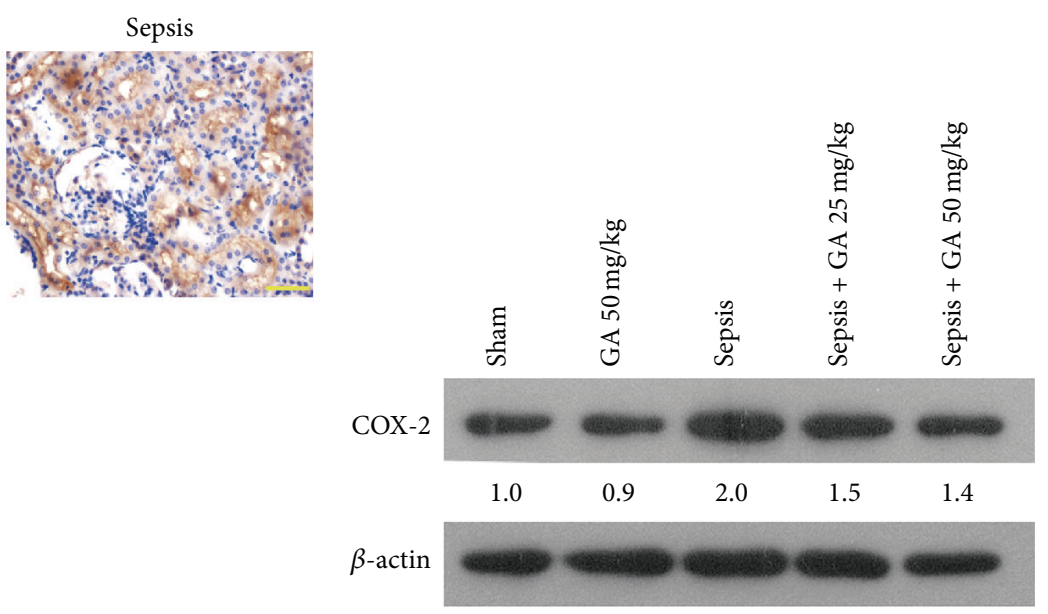

(f)

FIgURE 4: GA inhibited the productions of NO and $\mathrm{PGE}_{2}$ and expressions of iNOS and COX-2 in kidney tissue induced by AKI. (a) The amount of nitrite in the kidney tissue was detected by the Griess Reagent System. (b) The concentration of $\mathrm{PGE}_{2}$ in kidney from different groups. The expression of iNOS in kidney was measured by immunohistochemical staining (magnification 400x) (b) and western blot (c). The expression of COX-2 in kidney was measured by immunohistochemical staining (magnification 400x) (d) and western blot (e). The results shown are representative of at least three independent experiments. Each value represents the mean $\pm \operatorname{SD}(n=6)$. ${ }^{* * *} P<0.001$, versus the sham operation group. ${ }^{\#} P<0.05 ;{ }^{\# \#} P<0.01 ;{ }^{\# \#} P<0.001$, versus the sepsis group. 

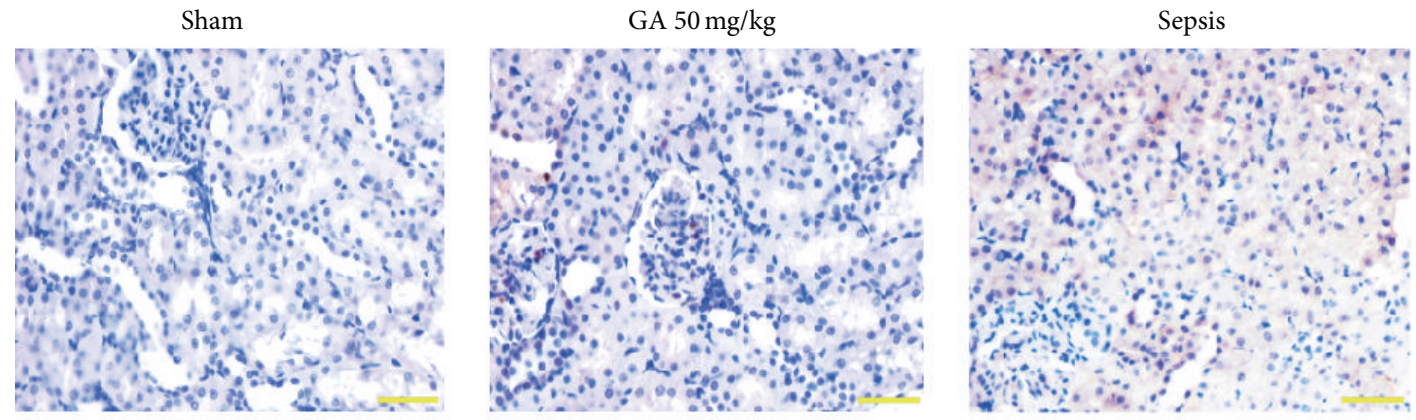

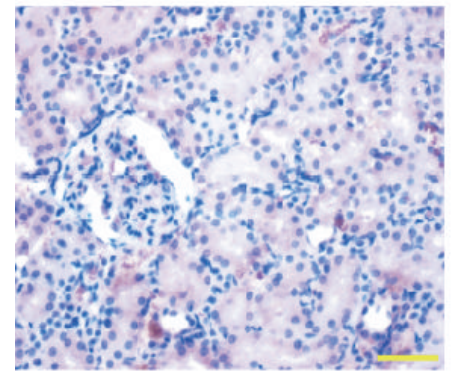

Sepsis $+25 \mathrm{mg} / \mathrm{kg}$

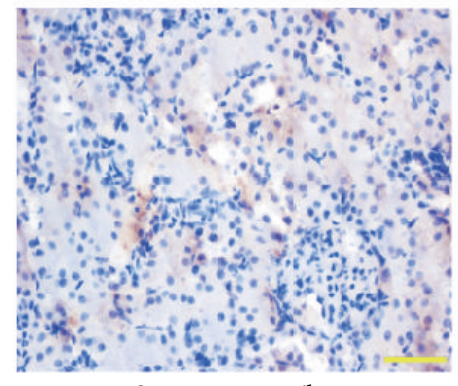

Sepsis $+50 \mathrm{mg} / \mathrm{kg}$

(a)

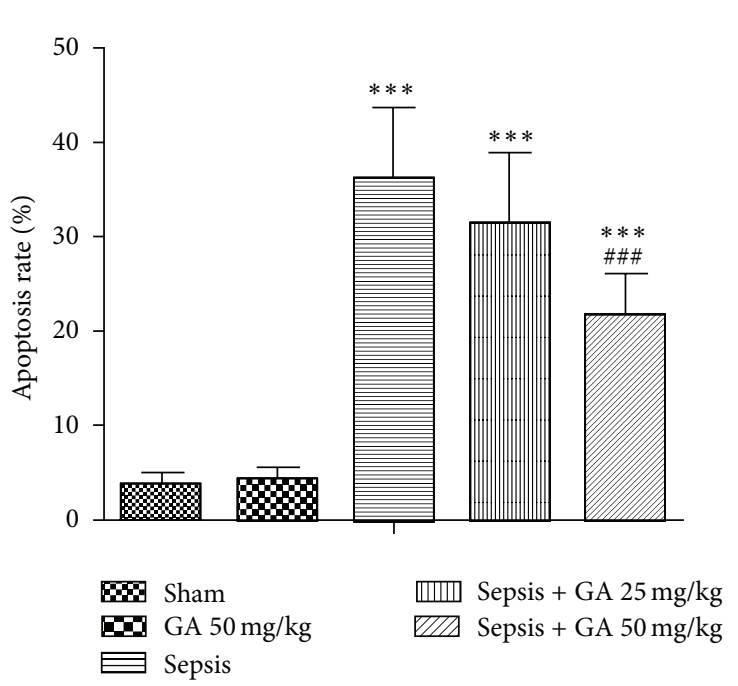

(b)

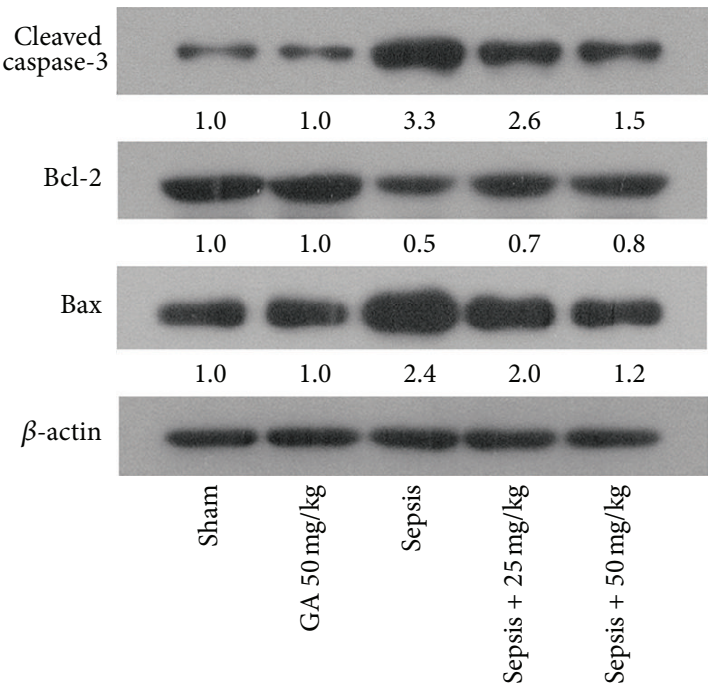

(c)

FIgURE 5: GA inhibited the apoptosis induced by AKI in kidney tissue. (a) The apoptosis of cells in kidney tissue was detected by TUNEL staining (magnification 400x). (b) The apoptosis rate of TUNEL staining from different groups was calculated. (c) Apoptosis-related proteins were detected by western blot. $\beta$-actin was used as a loading control. The results shown are representative of at least three independent experiments. Each value represents the mean $\pm \mathrm{SD}(n=6) .{ }^{* * *} P<0.001$, versus the sham operation group. ${ }^{\# \# \#} P<0.001$ versus the sepsis group.

\section{Discussion}

AKI is a common complication of sepsis [21]. Sepsis-induced AKI may cause multiple organ failure in critical ill patients and the mortality rate is high. Therefore, it is of important clinical significance to explore the prevention and control measures. Recent studies have shown that GA has a variety of protective effects on kidney. Based on the above, in this study, we evaluate the effect of GA on sepsis-induced AKI in rats.
We established the sepsis-induced AKI model by CLP in rats, which is one of the classical methods for sepsis and also the animal model most close to pathophysiological procedure of sepsis [22]. Kidney is the most sensitive organ in sepsis. After CLP, the serum Cre and BUN levels were significantly increased and renal tubule epitheliums were swelling with inflammatory cell infiltration in kidney, which finally resulted in AKI. Numerous studies have shown that mild loss of kidney function may increase the fatality rate of patients with 


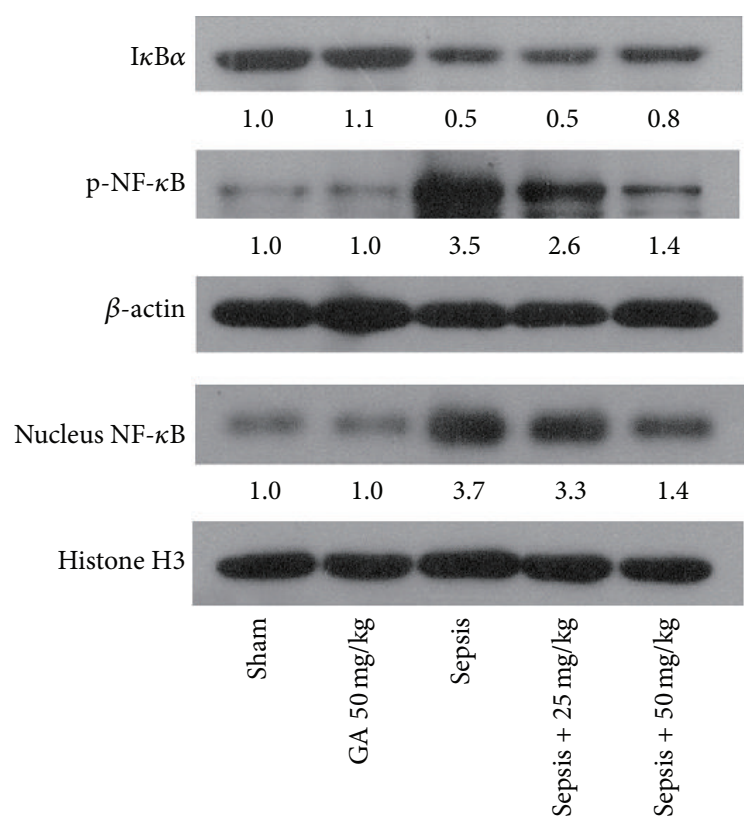

(a)

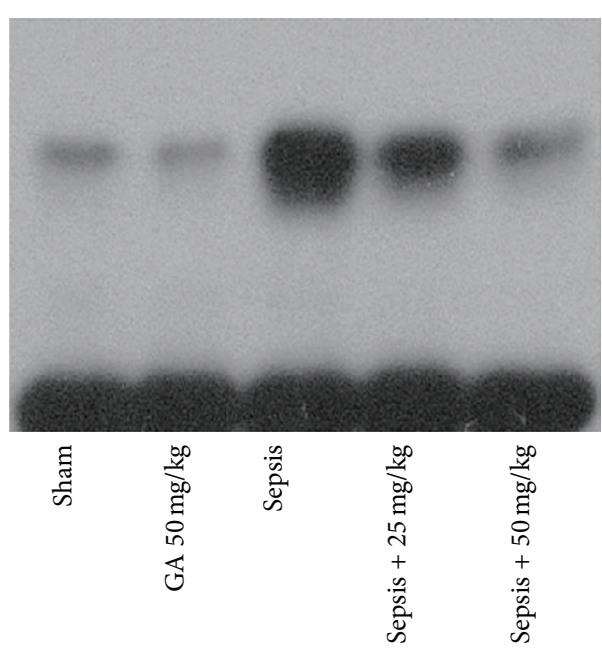

(b)

FIGURE 6: GA inhibited the activation of NF- $\kappa$ B induced by AKI. (a) The expression of NF- $\kappa$ B signaling pathway related proteins was detected by western blot. $\beta$-actin and Histone $\mathrm{H} 3$ were used as a loading control. (b) The transcription activity of NF- $\kappa \mathrm{B}$ inhibited by GA in kidney tissue was detected by EMSA assay. The results shown are representative of at least three independent experiments.

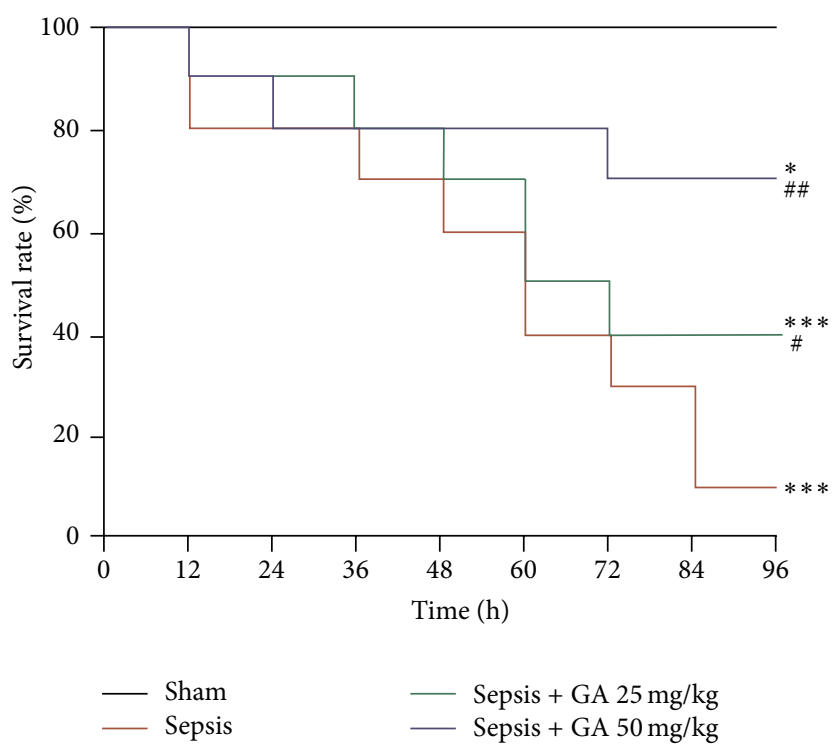

FIGURE 7: The survival rate of rats in different treatment groups. The survival curves of rats $(n=10)$ with indicated treatment were monitored. ${ }^{*} P<0.05 ;{ }^{* * *} P<0.001$, versus the sham operation group. ${ }^{\#} P<0.05 ;{ }^{\# \#} P<0.01$, versus the sepsis group.

sepsis [23]. So the early intervention in AKI with proper treatment will help reduce the mortality of sepsis patients. The preventive effect of GA against AKI was confirmed in our study by reducing pathological changes and improving renal function. Thus, we conclude that GA has real potential as a new medical treatment in sepsis-induced AKI. However, the possible mechanism of GA alleviating AKI was not clear, so we next performed various experiments to further explore it.
The essence of sepsis is the systemic inflammatory reaction and the inflammatory cytokines and mediators play important roles in pathogenesis of sepsis. TNF- $\alpha$, IL- 6 , and IL- $1 \beta$ are the main inflammatory cytokines released in sepsis [24-26], which may assess the severity of sepsis. The cascade activation and interaction of inflammatory cytokines and mediators promote the formation of inflammatory cascade and finally lead to SIRS. In the present study, the productions 
of TNF- $\alpha$, IL-1 $\beta$, and IL- 6 were significantly induced by AKI, which were suppressed by the treatment of GA. The inflammatory cytokine levels were consistent with the extent of renal injury, proving the anti-inflammatory effects of GA in vivo.

NO is derived from the oxidation of L-arginine, which is catalyzed by nitric oxide synthase (NOS). In sepsis, the expression of inducible nitric oxide synthase (iNOS) induced by inflammatory mediators and cytokines is significantly increased in immunocytes, such as neutrophils and macrophages. Researches have found that iNOS induced the production of $\mathrm{NO}$ and caused the oxidized stress in sepsis-induced AKI [27, 28]. Meanwhile, the studies about NOS inhibitor have confirmed the effect of iNOS on the development of AKI [29]. Study by Heemskerk et al. showed that selective iNOS inhibitor could prevent renal proximal tubule damage [30]. In the present study, the production of $\mathrm{NO}$ and expression of iNOS were significantly induced by AKI, which were suppressed by the treatment of GA. COX-2 is one of the downstream targets of NO and there is almost no expression in normal tissues. Under stimulation, COX-2 is largely expressed in immune cells and participates in and aggravates the inflammatory response. The level of COX-2 is associated with the severity of inflammation [31]. $\mathrm{PGE}_{2}$, an enzymatic product of COX-2, is an important inflammatory mediator and plays an important role in the inflammatory response [32]. Similarly, in our study, the production of $\mathrm{PGE}_{2}$ and expression of COX-2 were significantly induced by AKI, which were suppressed by the treatment of GA.

Recent studies have found that the apoptosis of renal tubular epithelial cells was the primary mechanisms of AKI. At early phase of sepsis, the number of apoptosis cells in kidney was significantly increased, which were closely connected with large releases of cytokines. Meanwhile, ischemicreperfusion injury can promote the level of apoptosis in renal tubular epithelial cells. Study by Cunningham et al. showed that, in sepsis-induced AKI, apoptosis was found in kidney after $6 \mathrm{~h}$ of stimulation of LPS [33]. Jo et al. found that the apoptosis of renal tubular cells induced by inflammatory cytokines can be one of the possible mechanisms of renal dysfunction in endotoxemia [34]. Consistent with these results, obvious apoptosis induced by AKI was found in renal tissue in our study, which could be inhibited by GA treatment. Furthermore, we investigated the apoptosis signaling pathway through which GA could play a role in antiapoptosis. The apoptosis of renal tubular epithelial cells is induced through two major apoptosis signaling pathways, namely, the intrinsic mitochondrial pathway and the extrinsic death receptor pathway. Caspase-3, as a downstream component in the intrinsic and extrinsic apoptotic pathways, is an executioner caspase. The inhibition of caspase- 3 activation can prevent cells from apoptosis. Bcl-2 family proteins are the most important apoptosis-related genes. Bcl-2 suppresses cell apoptosis via inhibiting the production of free radicals, decreasing mitochondrial membrane permeability, obstructing the release of cytochrome $\mathrm{C}$, and activation of caspase. The ratio of $\mathrm{Bcl}-2 / \mathrm{Bax}$ determines the survival of the cells [35]. In our present study, GA significantly inhibited the activation of caspase- 3 induced by AKI and increased the ratio of Bcl-2/Bax, which further confirmed the effect of GA against apoptosis.

$\mathrm{NF}-\kappa \mathrm{B}$ is the key transcriptional regulatory factor of genes related to inflammation, which plays important roles in the development and progression of sepsis by inducing the transcription of inflammatory cytokines and starting the inflammatory cascade reactions [36]. In sepsis, the release of toxin and inflammatory mediators in the body can induce the degradation of $I \kappa B$ and then free and activate NF- $\kappa$ B. The activated NF- $\kappa$ B quickly enters into nucleus across nuclear pore and induces the expression of TNF- $\alpha$, IL- 6 , and so forth. The released cytokines can conversely activate NF- $\kappa \mathrm{B}$ and finally form cascade amplification effect of the positive feedback. So the activation of NF- $\kappa$ B is key link of triggering excessive inflammatory responses. In experimental animal models of ALI, NF- $\kappa$ B activation is increased [37]. Aosasa et al. found that the inhibitory effect of gabexate mesilate on the TNF- $\alpha$ production of activated human monocytes is mediated by the suppression of NF- $\kappa \mathrm{B}$ activation [38]. iNOS and COX-2 are two important proteins downstream from $\mathrm{NF}-\kappa \mathrm{B}$ signaling pathway and the NF- $\kappa \mathrm{B}$ could specifically bind to the promoter sequence of iNOS and COX-2, which promotes the transcription of them and ultimately facilitates the production of $\mathrm{NO}$ and $\mathrm{PGE}_{2}$. Surh et al. found that COX2 and iNOS were downregulated through suppression of NF$\kappa \mathrm{B}$ activation [39]. A study by Moriyuki et al. demonstrated that the inhibition of NF- $\kappa \mathrm{B}$ signaling pathway restrained the catalytic function of COX-2 so that the production of $\mathrm{PGE}_{2}$ was decreased [40]. In the present study, the degradation of $\mathrm{I} \kappa \mathrm{B} \alpha$ and activation of NF- $\kappa \mathrm{B}$ were found in sepsis group, and the activation of NF- $\kappa \mathrm{B}$ was inhibited by GA treatment, suggesting that inhibition of NF- $\kappa \mathrm{B}$ suppressed the production of inflammatory cytokines and mediators induced by sepsis and played a key role in the protective effects of GA on AKI.

\section{Conclusion}

We have demonstrated the protective role of GA against sepsis-induced AKI by alleviating the pathological damage of kidney tissue, inhibiting the release of inflammatory cytokines and mediators, suppressing the kidney cells apoptosis, and inactivating NF- $\kappa$ B. Our study indicates that treatment with GA might be a potential approach in the treatment of sepsis-induced AKI.

\section{Conflict of Interests}

The authors declare that there is no conflict of interests regarding the publication of this paper.

\section{Acknowledgment}

This study was supported by a grant from the National Key Clinical Specialties of Ministry of Health (no. 2012-649). 


\section{References}

[1] D. E. Fry, "Sepsis, systemic inflammatory response, and multiple organ dysfunction: the mystery continues," American Surgeon, vol. 78, no. 1, pp. 1-8, 2012.

[2] P. S. Tipler, J. Pamplin, V. Mysliwiec, D. Anderson, and C. A. Mount, "Use of a protocolized approach to the management of sepsis can improve time to first dose of antibiotics," Journal of Critical Care, vol. 28, no. 2, pp. 148-151, 2013.

[3] K. Grozdanovski, Z. Milenkovic, I. Demiri, and K. Spasovska, "Prediction of outcome from community-acquired severe sepsis and septic shock in tertiary-care university hospital in a developing country," Critical Care Research and Practice, vol. 2012, Article ID 182324, 6 pages, 2012.

[4] H. L. Cronshaw, R. Daniels, A. Bleetman, E. Joynes, and M. Sheils, "Impact of the surviving sepsis campaign on the recognition and management of severe sepsis in the emergency department: are we failing?" Emergency Medicine Journal, vol. 28, no. 8, pp. 670-675, 2011.

[5] R. S. Hotchkiss, G. Monneret, and D. Payen, "Immunosuppression in sepsis: a novel understanding of the disorder and a new therapeutic approach," The Lancet Infectious Diseases, vol. 13, no. 3, pp. 260-268, 2013.

[6] S. M. Bagshaw, C. George, and R. Bellomo, "Early acute kidney injury and sepsis: a multicentre evaluation," Critical Care, vol. 12, no. 2, article R47, 2008.

[7] S. Rajapakse, C. Rodrigo, A. Rajapakse, D. Kirthinanda, and S. Wijeratne, "Renal replacement therapy in sepsis-induced acute renal failure," Saudi Journal of Kidney Diseases and Transplantation, vol. 20, no. 4, pp. 553-559, 2009.

[8] L. Wu, N. Gokden, and P. R. Mayeux, "Evidence for the role of reactive nitrogen species in polymicrobial sepsis-induced renal peritubular capillary dysfunction and tubular injury," Journal of the American Society of Nephrology, vol. 18, no. 6, pp. 1807-1815, 2007.

[9] N. Abe, T. Ebina, and N. Ishida, "Interferon induction by glycyrrhizin and glycyrrhetinic acid in mice," Microbiology and Immunology, vol. 26, no. 6, pp. 535-539, 1982.

[10] M. Baba and S. Shigeta, "Antiviral activity of glycyrrhizin against varicella-zoster virus in vitro," Antiviral Research, vol. 7, no. 2, pp. 99-107, 1987.

[11] L. J. Ming and A. C. Y. Yin, “Therapeutic effects of glycyrrhizic acid," Natural Product Communications, vol. 8, no. 3, pp. 415418, 2013.

[12] O. A. Pliasunova, T. V. Il'ina, I. Kiseleva et al., "The antiHIV activity of glycyrrhizic acid penta-O-nicotinate," Vestnik Rossiǔskoı̆ Akademii Meditsinskikh Nauk, no. 11, pp. 42-46, 2004.

[13] Z. Y. Wang and D. W. Nixon, "Licorice and cancer," Nutrition and Cancer, vol. 39, no. 1, pp. 1-11, 2001.

[14] Y. Arase, K. Ikeda, N. Murashima et al., "The long term efficacy of glycyrrhizin in chronic hepatitis C patients," Cancer, vol. 79, no. 8, pp. 1494-1500, 1997.

[15] T. G. J. van Rossum, A. G. Vulto, W. C. J. Hop, and S. W. Schalm, "Glycyrrhizin-induced reduction of ALT in European patients with chronic hepatitis C," American Journal of Gastroenterology, vol. 96, no. 8, pp. 2432-2437, 2001.

[16] K.-L. Li, J.-G. Zhang, H.-M. Wang, and J. Chen, "The effects of glycyrrhizin-18alpha on the expression of NF-kappaB in the renal interstitium of rats with obstructive nephropathy," Xi Bao Yu Fen Zi Mian Yi Xue Za Zhi, vol. 20, no. 1, pp. 31-33, 2004.

[17] S. Hou, F. Zheng, Y. Li, L. Gao, and J. Zhang, "The protective effect of glycyrrhizic acid on renal tubular epithelial cell injury induced by high glucose," International Journal of Molecular Sciences, vol. 15, no. 9, pp. 15026-15043, 2014.

[18] X. Bi, G. Zhu, Z. Han et al., "Protective effect of glycyrrhizin on nephrotic syndrome induced by adriamycin in rats," Clinical and Investigative Medicine, vol. 32, no. 3, pp. E229-E238, 2009.

[19] K. Doi, A. Leelahavanichkul, P. S. T. Yuen, and R. A. Star, "Animal models of sepsis and sepsis-induced kidney injury," The Journal of Clinical Investigation, vol. 119, no. 10, pp. 2868-2878, 2009.

[20] T. Miyaji, X. Hu, P. S. T. Yuen et al., "Ethyl pyruvate decreases sepsis-induced acute renal failure and multiple organ damage in aged mice," Kidney International, vol. 64, no. 5, pp. 1620-1631, 2003.

[21] R. Hilton, "Defining acute renal failure," CMAJ, vol. 183, no. 10, pp. 1167-1169, 2011.

[22] W. J. Hubbard, M. Choudhry, M. G. Schwacha et al., "Cecal ligation and puncture," Shock, vol. 24, supplement 1, pp. 52-57, 2005.

[23] G. M. Chertow, E. Burdick, M. Honour, J. V. Bonventre, and D. W. Bates, "Acute kidney injury, mortality, length of stay, and costs in hospitalized patients," Journal of the American Society of Nephrology, vol. 16, no. 11, pp. 3365-3370, 2005.

[24] A. Grenz, J.-H. Kim, J. D. Bauerle, E. Tak, H. K. Eltzschig, and E. T. Clambey, "Adora2b adenosine receptor signaling protects during acute kidney injury via inhibition of neutrophildependent TNF- $\alpha$ release," Journal of Immunology, vol. 189, no. 9, pp. 4566-4573, 2012.

[25] J.-W. Lee, W.-J. Nam, M.-J. Han et al., "Role of IL-1alpha in cisplatin-induced acute renal failure in mice," Korean Journal of Internal Medicine, vol. 26, no. 2, pp. 187-194, 2011.

[26] S. J. Lee, E. Borsting, A.-E. Declèves, P. Singh, and R. Cunard, "Podocytes express IL-6 and lipocalin 2/neutrophil gelatinase-associated lipocalin in lipopolysaccharide-induced acute glomerular injury," Nephron-Experimental Nephrology, vol. 121, no. 3-4, pp. e86-e96, 2012.

[27] S. Heemskerk, R. Masereeuw, F. G. M. Russel, and P. Pickkers, "Selective iNOS inhibition for the treatment of sepsis-induced acute kidney injury," Nature Reviews Nephrology, vol. 5, no. 11, pp. 629-640, 2009.

[28] B. Hauser, H. Bracht, M. Matejovic, P. Radermacher, and B. Venkatesh, "Nitric oxide synthase inhibition in sepsis? Lessons learned from large-animal studies," Anesthesia and Analgesia, vol. 101, no. 2, pp. 488-498, 2005.

[29] M. M. Tiwari, R. W. Brock, J. K. Megyesi, G. P. Kaushal, and P. R. Mayeux, "Disruption of renal peritubular blood flow in lipopolysaccharide-induced renal failure: role of nitric oxide and caspases," The American Journal of Physiology - Renal Physiology, vol. 289, no. 6, pp. F1324-F1332, 2005.

[30] S. Heemskerk, P. Pickkers, M. P. W. J. M. Bouw et al., "Upregulation of renal inducible nitric oxide synthase during human endotoxemia and sepsis is associated with proximal tubule injury," Clinical Journal of the American Society of Nephrology, vol. 1, no. 4, pp. 853-862, 2006.

[31] D. A. Kniss, "Cyclooxygenases in reproductive medicine and biology," Journal of the Society for Gynecologic Investigation, vol. 6, no. 6, pp. 285-292, 1999.

[32] C. F. Nathan, "Secretory products of macrophages," Journal of Clinical Investigation, vol. 79, no. 2, pp. 319-326, 1987.

[33] P. N. Cunningham, H. M. Dyanov, P. Park, J. Wang, K. A. Newell, and R. J. Quigg, "Acute renal failure in endotoxemia is caused by TNF acting directly on TNF receptor-1 in kidney," Journal of Immunology, vol. 168, no. 11, pp. 5817-5823, 2002. 
[34] S. K. Jo, D. R. Cha, W. Y. Cho et al., "Inflammatory cytokines and lipopolysaccharide induce fas-mediated apoptosis in renal tubular cells," Nephron, vol. 91, no. 3, pp. 406-415, 2002.

[35] J. M. Adams and S. Cory, "Life-or-death decisions by the Bcl-2 protein family," Trends in Biochemical Sciences, vol. 26, no. 1, pp. 61-66, 2001.

[36] M. Adamzik, S. Schäfer, U. H. Frey et al., "The NFKB1 promoter polymorphism (-94ins/delATTG) alters nuclear translocation of NF- $\kappa \mathrm{B} 1$ in monocytes after lipopolysaccharide stimulation and is associated with increased mortality in sepsis," Anesthesiology, vol. 118, no. 1, pp. 123-133, 2013.

[37] M. Xu, F. Cao, L. Liu et al., "Tanshinone IIA-induced attenuation of lung injury in endotoxemic mice is associated with reduction of hypoxia-inducible factor $1 \alpha$ expression," American Journal of Respiratory Cell and Molecular Biology, vol. 45, no. 5, pp. 10281035, 2011.

[38] S. Aosasa, S. Ono, H. Mochizuki, H. Tsujimoto, C. Ueno, and A. Matsumoto, "Mechanism of the inhibitory effect of protease inhibitor on tumor necrosis factor alpha production of monocytes," Shock, vol. 15, no. 2, pp. 101-105, 2001.

[39] Y.-J. Surh, K.-S. Chun, H.-H. Cha et al., "Molecular mechanisms underlying chemopreventive activities of anti-inflammatory phytochemicals: down-regulation of COX-2 and iNOS through suppression of NF- $\kappa$ B activation," Mutation Research, vol. 480481, pp. 243-268, 2001.

[40] K. Moriyuki, F. Sekiguchi, K. Matsubara, H. Nishikawa, and A. Kawabata, "Curcumin inhibits the proteinase-activated receptor-2-triggered prostaglandin $\mathrm{E}_{2}$ production by suppressing cyclooxygenase- 2 upregulation and Akt-dependent activation of nuclear factor- $\kappa$ B in human lung epithelial cells," Journal of Pharmacological Sciences, vol. 114, no. 2, pp. 225-229, 2010. 


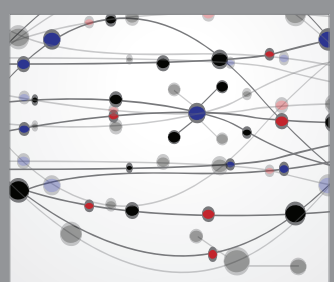

The Scientific World Journal
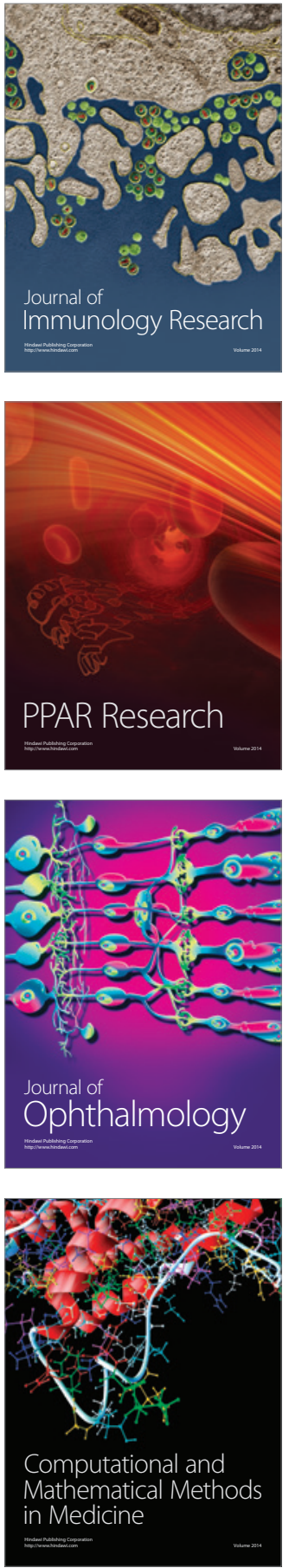

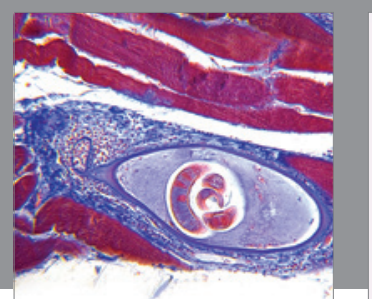

Gastroenterology Research and Practice

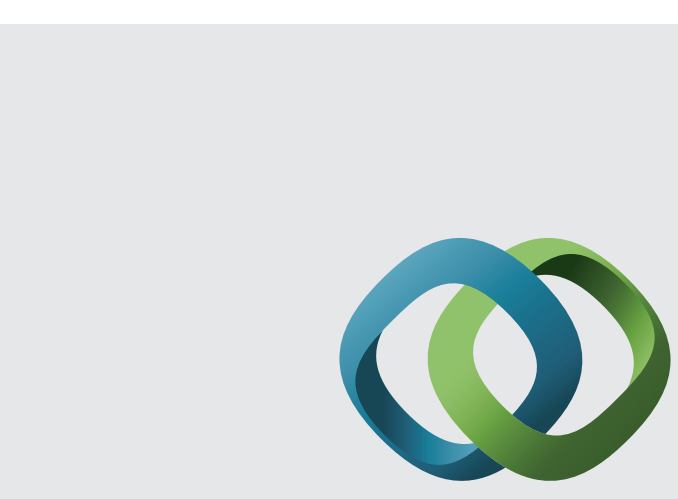

\section{Hindawi}

Submit your manuscripts at

http://www.hindawi.com
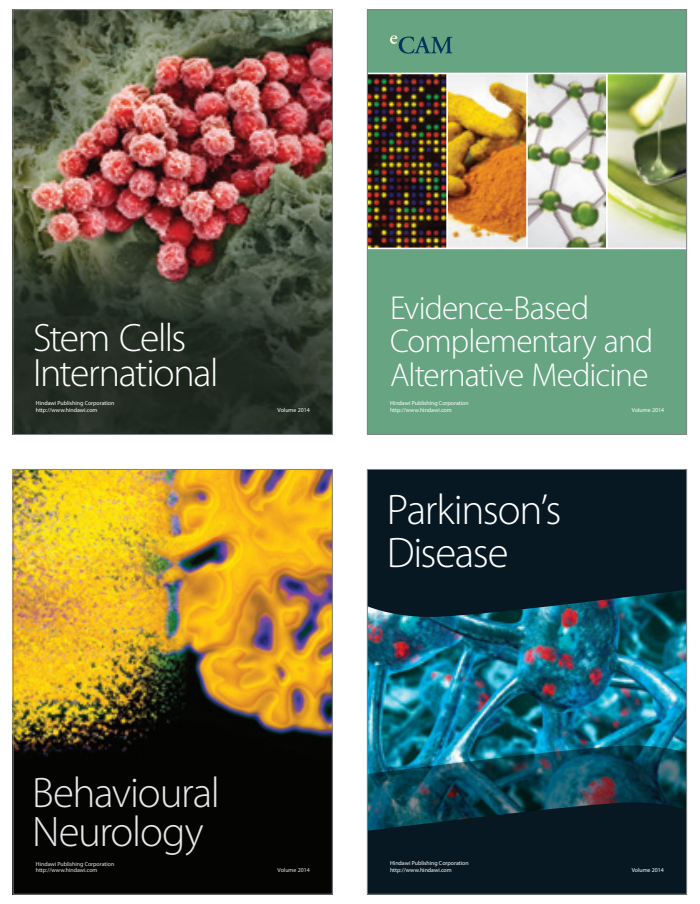
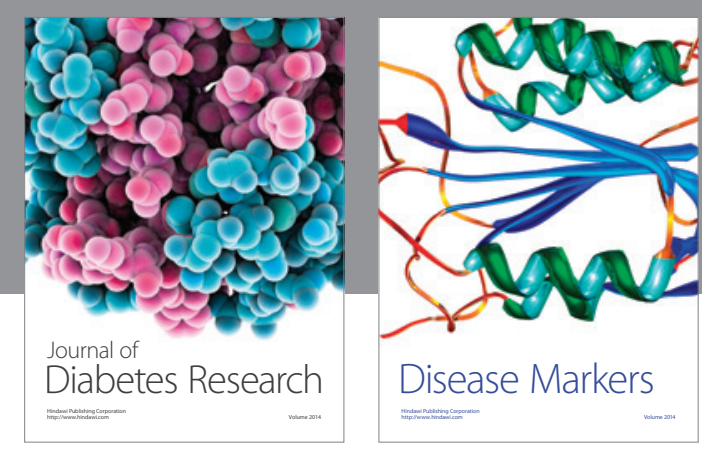

Disease Markers
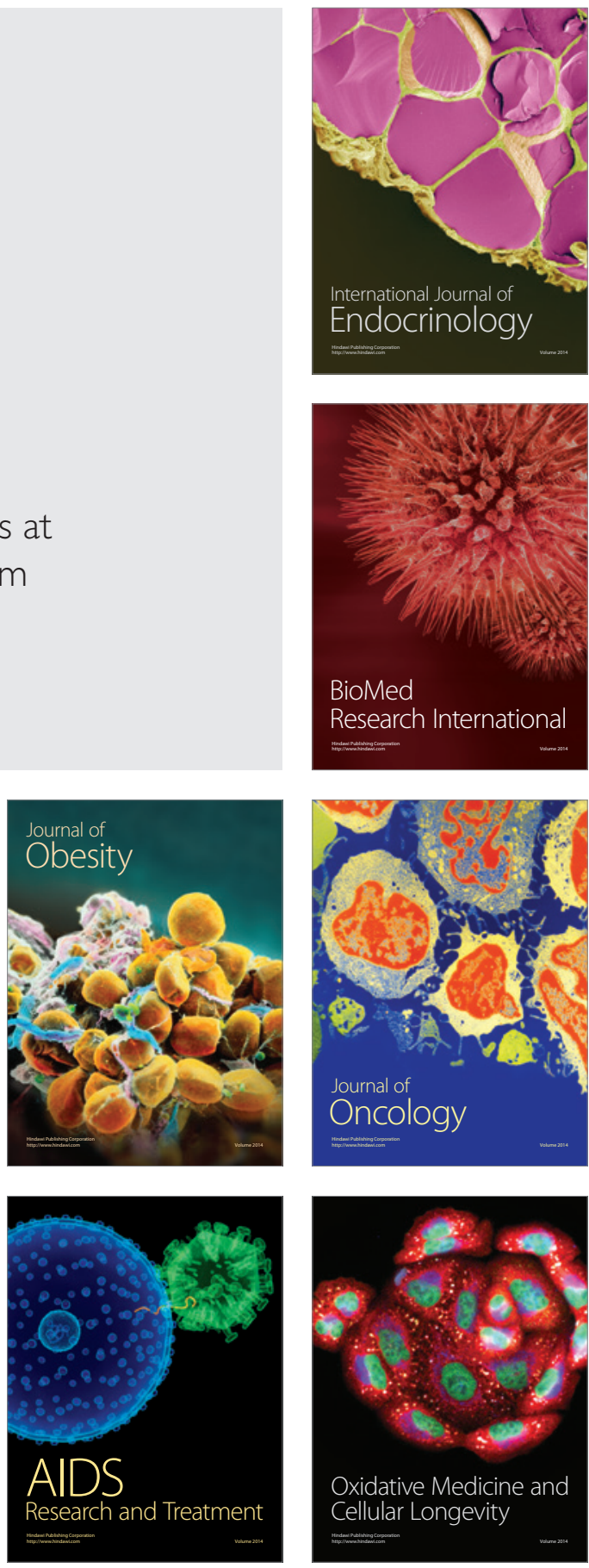